\title{
A New Species of Rhacophorus from Eastern Thailand (Anura: Rhacophoridae)
}

\author{
Masafumi Matsui ${ }^{1 *}$ and Somsak Panha ${ }^{2}$ \\ ${ }^{1}$ Graduate School of Human and Environmental Studies, Kyoto University, Sakyo-ku, \\ Kyoto 606-8501, Japan \\ ${ }^{2}$ Department of Biology, Faculty of Science, Chulalongkorn University, \\ Bangkok 10330, Thailand
}

\begin{abstract}
A new tree frog of the genus Rhacophorus is described on the basis of specimens collected from Kalasin and Roi Et Provinces, eastern Thailand. It can be distinguished from all other congeners by the combination of: moderate body size (about $38 \mathrm{~mm}$ in males and $44 \mathrm{~mm}$ in females); brownish dorsum with irregular, dark marking; third finger webbed broadly to base of disk or less on outer side, and fourth finger to distal subarticular tubercle or base of disk; and no dermal appendage on snout, vent, or heel. It is currently known only around the type locality, where habitats suitable for anurans are limited.
\end{abstract}

Key words: biogeography, classification, Polypedates, Southeast Asia, taxonomy

\section{INTRODUCTION}

The tree frog genus Rhacophorus Kuhl and Van Hasselt, 1822 (sensu lato) occurs in tropical to temperate regions of the Old World (Duellman, 1999). Liem (1970) split larger-sized rhacophorid members into two genera, Rhacophorus and Polypedates Tschudi, 1838, on the basis of a phenetic analysis of morphological characters; however, more than three decades after Liem's (1970) revision, classification of the Old World treefrogs is still unstable (cf. Wilkinson et al., 2002; Matsui and Orlov, 2004). Some authors combine the two genera and admit only Rhacophorus (e.g., Tian and Jiang, 1986; Dubois, 1987; Fei et al., 2004), while others recognize the validity of two genera (e.g., Frost, 1985; Jiang et al., 1987; Zhao and Adler, 1993; Inger et al., 1999; Maeda and Matsui, 1999; Malkmus et al., 2002). This conflict mainly derives from ambiguous morphological and ecological distinctions between the two genera, due mainly to inadequate species sampling for comparisons, and some Chinese Polypedates species with a green dorsum require taxonomic reassessment (Matsui and Wu, 1994). Even so, Liem (1970) could differentiate the two lineages by some osteological characters in the specimens examined.

Setting these taxonomic problems aside, the genus Rhacophorus (sensu stricto) includes about 60 species (Frost, 2004), of which quite a few have been added recently from regions of Southeast Asia already well surveyed (e.g., Manthey and Steiof, 1998; Inger et al., 1999; Matsui, 2000; Harvey et al., 2002). This situation holds for Thailand, where recent extensive field surveys have resulted in the discovery of new taxa or separation of cryptic taxa in frogs of different lineages (Matsui et al., 1996, 1998,

\footnotetext{
${ }^{*}$ Corresponding author. Phone: $+81-75-753-6846$; Fax : +81-75-753-6846;

E-mail: fumi@zoo.zool.kyoto-u.ac.jp
}

1999, 2005). During our survey of eastern Thailand in the autumn of 1996, we collected several specimens of a Rhacophorus distinctly different from its congeners hitherto known from Thailand (Taylor, 1962). These specimens, which resemble some Bornean or Sumatran members of this genus, but are easily distinguished morphologically from them, are described below as a new species.

\section{MATERIALS AND METHODS}

We conducted fieldwork in the Phu Sri Tan Wildlife Sanctuary, Kalasin Province, and Phu Pha Namtip Non-hunting Area, Roi Et Province, eastern Thailand, from 24-27 October 1996. Specimens were fixed in $10 \%$ formalin and later preserved in $70 \%$ ethanol. We took 18 body measurements (Table 1 ) to the nearest $0.1 \mathrm{~mm}$ with dial calipers under a binocular dissecting microscope: snout-vent length (SVL); head length ( $\mathrm{HL})$, from tip of snout to hind border of angle of jaw (not measured parallel with the median line); snout length (SL); eye length (EL); tympanum-eye distance (T-EL); tympanum diameter (TD); head width (HW); internarial distance (IND); interorbital distance (IOD); upper eyelid width (UEW); forelimb length (FLL); third finger disk width (3FDW); hindlimb length (HLL); tibia length ( $T L$ ); foot length (FL) from proximal end of inner metatarsal tubercle to tip of fourth toe; fourth toe disk width (4TDW); first toe length (1TL) from distal end of inner metatarsal tubercle to tip of first toe; inner metatarsal tubercle length (IMTL). These measurements mainly followed the defnintions by Matsui (1984). We also prepared radiographs to examine gross osteology. Finally, we examined museum specimens, including some types, of many described taxa of the genus Rhacophorus (sensu stricto), for comparisons (see Appendix 1 in Matsui and Orlov, 2004).

\section{SYSTEMATICS}

Rhacophorus jarujini sp. nov.

(Figs. 1, 2)

Diagnosis. The new species is assigned to Rhacophorus (sensu stricto) by: vertebrae procoelous; frontoparietal lacking parieto-squamosal arch; distal end of terminal phalanx Y-shaped. It is distinguished from all other congeners 
Table 1. Measurements of 18 characters in Rhacophorus jarujini. SVL (means \pm SD, in $\mathrm{mm}$ ) and medians of ratios $(R)$ of other characters to $S V L$, followed by ranges in parenthesis. See text for character abbreviations.

\begin{tabular}{|c|c|c|c|c|c|c|c|}
\hline & & $\overline{S V L}$ & $\mathrm{RHL}$ & $\mathrm{RSL}$ & REL & RT-EL & RTD \\
\hline \multirow[t]{2}{*}{ Males } & $(\mathrm{N}=4)$ & $37.6 \pm 2.9$ & 37.2 & 17.0 & 14.2 & 1.5 & 7.9 \\
\hline & & $(33.7-40.0)$ & $(36.4-38.6)$ & $(15.6-17.2)$ & $(13.5-15.7)$ & $(1.2-1.9)$ & $(7.5-8.8)$ \\
\hline \multirow[t]{3}{*}{ Females } & $(\mathrm{N}=5)$ & $43.6 \pm 1.6$ & 36.2 & 16.1 & 14 & 1.6 & 7.8 \\
\hline & & $(41.5-46.1)$ & $(34.1-37.0)$ & $(15.0-17.1)$ & $(12.5-15.2)$ & $(1.0-2.3)$ & $(6.3-8.1)$ \\
\hline & & $\mathrm{RHW}$ & RIND & RIOD & RUEW & RFLL & R3FDW \\
\hline \multirow[t]{2}{*}{ Males } & $(\mathrm{N}=4)$ & 37.2 & 10.1 & 11.9 & 9.3 & 67.0 & 7.3 \\
\hline & & $(36.8-39.8)$ & $(9.8-10.5)$ & $(10.5-12.8)$ & $(8.3-10.8)$ & (63.2-70.3) & $(6.6-7.7)$ \\
\hline \multirow[t]{3}{*}{ Females } & $(\mathrm{N}=5)$ & 37.1 & 8.9 & 12.4 & 8.7 & 68.0 & 6.9 \\
\hline & & $(34.5-37.6)$ & $(8.3-10.3)$ & $(10.8-12.9)$ & $(8.3-9.9)$ & $(56.0-69.7)$ & $(6.5-6.9)$ \\
\hline & & R4TDW & RHLL & RTL & $\mathrm{RFL}$ & $\mathrm{R} 1 \mathrm{TL}$ & RITML \\
\hline \multirow[t]{2}{*}{ Males } & $(\mathrm{N}=4)$ & 4.9 & 163.4 & 52.8 & 44.6 & 12.8 & 4.4 \\
\hline & & $(4.3-5.9)$ & (154.5-172.7) & $(49.0-56.7)$ & $(41.7-47.8)$ & $(11.0-14.5)$ & $(3.5-4.5)$ \\
\hline \multirow[t]{2}{*}{ Females } & $(\mathrm{N}=5)$ & 5.0 & 167.8 & 54.4 & 47.9 & 13.7 & 4.6 \\
\hline & & $(4.6-5.5)$ & (147.3-178.9) & $(46.6-57.2)$ & $(40.1-49.0)$ & $(10.4-14.2)$ & $(4.1-5.1)$ \\
\hline
\end{tabular}

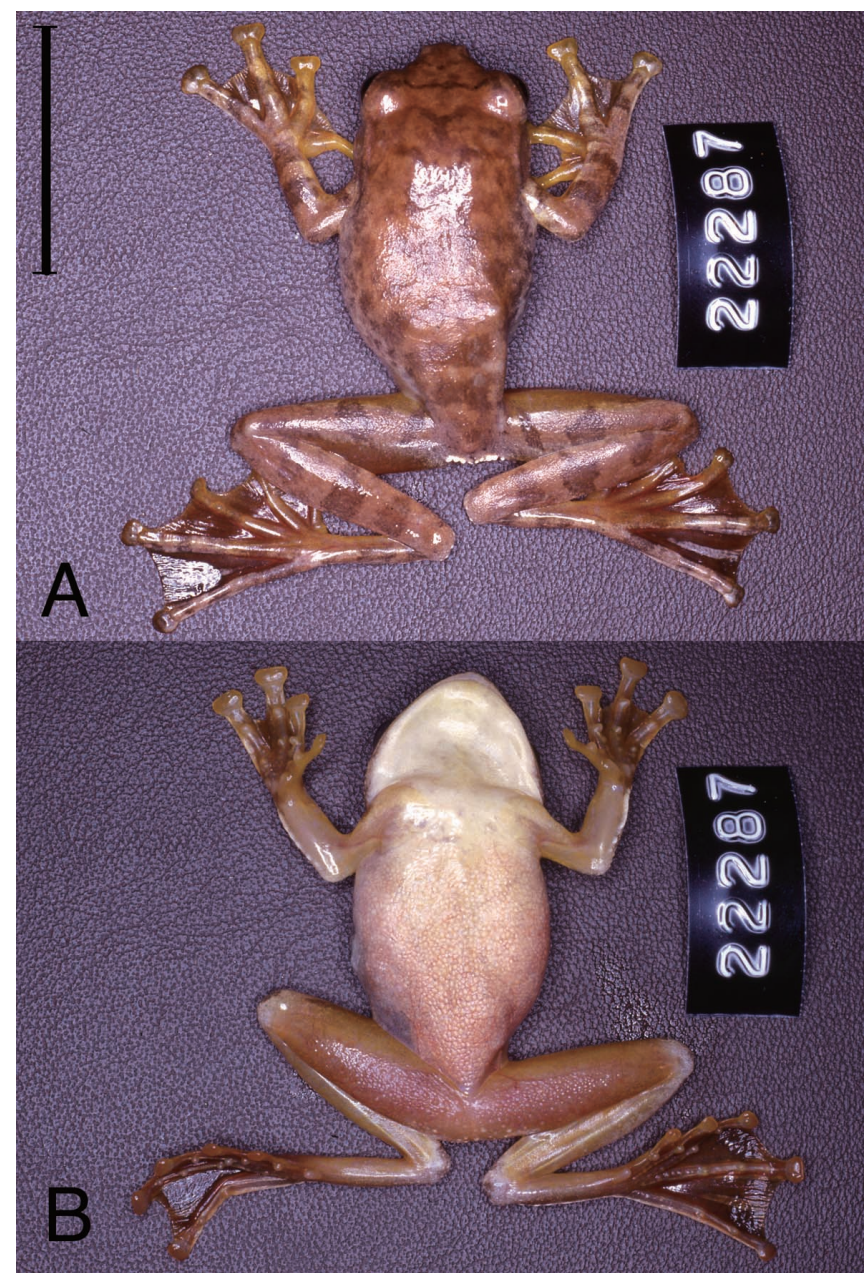

Fig. 1. Male paratype of Rhacophorus jarujini (KUHE 22287, $\mathrm{SVL}=33.7 \mathrm{~mm}$ ); (A) dorsal and $(\mathbf{B})$ ventral views. Scale bar indicates $20 \mathrm{~mm}$.

by the combination of (1) moderate size, with females from $41.5-46.1 \mathrm{~mm}$ and males from $33.7-40.0 \mathrm{~mm}$ in SVL, (2) dorsum brownish rather than greenish, with irregular dark marking, (3) third finger webbed broadly to base of disk or

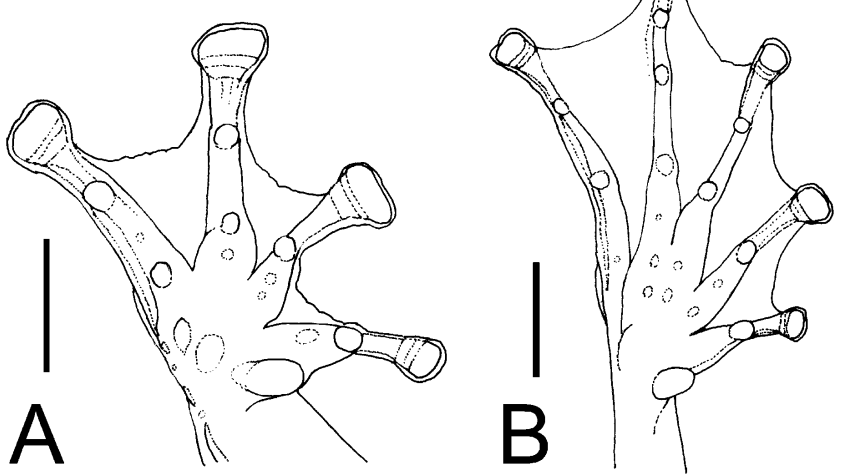

Fig. 2. Ventral views of (A) hand and (B) foot of male holotype (CUZM (A) 5251). Scale bar indicates $5 \mathrm{~mm}$.

less on outer side, and fourth finger to distal subarticular tubercle or base of disk, and (4) no dermal appendage on snout, vent, or heel.

Etymology. The specific name is dedicated to Mr. Jarujin Nabhitabhata of National Science Museum of Thailand, who is actively elucidating faunal diversity in Thailand.

Holotype. CUZM (Chulalongkorn University, Zoological Museum) (A) 5251, a male from Phu Sri Tan Wildlife Sanctuary $\left(104^{\circ} 10^{\prime} \mathrm{E}, 16^{\circ} 30^{\prime} \mathrm{N}, 500 \mathrm{~m}\right.$ a.s.I.), Kalasin Province, Thailand. Collected on 26 October 1996 by M. Matsui.

Paratypes. CUZM (A) 5252-5253, KUHE (Kyoto University, Human and Environmental Studies), 23038, three females; KUHE 23037, a male; and CUZM (A) 5254, a juvenile; all the same data as for holotype. KUHE 22280, 23045, two females, and KUHE 22287, 22288, two males, from Phu Pha Namtip Non-hunting area, Roi Et Province, collected on 25 October 1996 by M. Matsui.

Description of holotype (measurements in $\mathrm{mm}$ ). SVL 39.6; head about as long (14.4) as broad (14.6); snout (6.8) longer than eye (5.5), rounded dorsally and angular in profile, slightly pointed at tip and projecting slightly over lower jaw; canthus blunt; lores slightly oblique, slightly concave; nostril nearer to tip of snout than to eye; internarial distance 
(4.0) narrower than interorbital (4.8); latter wider than eyelid (3.8); eye diameter (5.4) larger than eye-nostril (4.2); tympanum distinct, length (3.5) more than three-fifths eye diameter and separated from eye by one-seventh the tympanum diameter (0.5); vomerine teeth in short, nearly horizontal groups beginning near anterior corners of choanae, groups separated by more than the length of one group; a longitudinal opening into median subgular vocal sac on both sides of mouth floor.

First finger shorter than second, length of first (3.9, measured from distal edge of inner palmar tubercle) shorter than diameter of eye; fourth finger longer than second; tips of fingers dilated into large disks, that of third finger (2.6) narrower than tympanum; broad web (Fig. 2A) reaching base of subarticular tubercle of first finger, proximal margin of tubercle on inner edge of second finger, and to bases of disk on outer edge of second, proximal margin of distal tubercle on inner edge of third, distal margin of distal tubercle on outer edge of third, and distal margin of distal tubercle on fourth finger; weak supernumerary tubercles on metacarpals; a distinct inner and a round, indistinct outer palmar tubercle.

Hindlimb (61.2) about 2.3 times length of forelimb (26.1); tibia not long (19.4), heels slightly overlapping when limbs are held at right angles to body; tibiotarsal articulation of adpressed limb reaching anterior rim of eye; foot (17.0) shorter than tibia; tips of toes expanded into disks smaller than those of fingers (disk diameter of fourth toe 1.7); all toes webbed to disks (Fig. 2B); subarticular tubercles indistinct; a small inner metatarsal tubercle, length (1.4) less than one-third the length of first toe (4.8), but no outer metatarsal tubercle.

Dorsum smooth, free of skull; an oblique fold from eye above tympanum, ending at above arm insertion; skin of throat smooth, abdomen coarsely granular; a weak fringe of skin from outer edge of fourth finger to elbow; hindlimb smooth, except for very narrow fringes of skin along inner edge of first toe and outer edge of fifth; no dermal appendages or large tubercles at vent and heel; nuptial pad absent.

Color in life. Dorsum light brown; a narrow darker brown bar crossing upper eyelids; back with irregular, darker brown crossbands; sides of face same shade of brown as dorsal surface of head; lips unpatterned; abdomen without markings, anteriorly cream and posteriorly yellow; ventral surfaces of thigh, hand, and foot light orange; iris yellow; a white line on supracloacal ridge; a dark brown marking around vent; limbs with dark crossbars, three bands crossing shank and two crossing antebrachium; posterior thigh orange-brown, without any definable pattern; webbing reddish-orange with a light brown streak.

Osteology. Vertebral column procoelous; frontoparietal lacking parieto-squamosal arch; distal end of the terminal phalanxY-shaped.

Variation. The average snout-vent length of five females (mean $\pm S D=43.6 \pm 1.6 \mathrm{~mm}$ ) is significantly larger than that of four males $(37.6 \pm 2.9 \mathrm{~mm}$; Student's t-test, $p<0.01)$, but no sexual difference was found in other measurements relative to SVL (Mann-Whitney $U$ test, $p>0.05$ ), possibly due to small sample size. A juvenile had a SVL of $26.8 \mathrm{~mm}$. Length of hindlimb varies slightly, and tibiotarsal articulation of adpressed limb reaches middle of eye in one, anterior rim of eye in four, between eye and nostril in three, and nostril in one individuals. Hand webbing is slightly better developed in some individuals than in the holotype, with broad web reaching base of disk on outer edge of third, and on inner edge of fourth finger. Individuals are nearly uniform in coloration and pattern of dorsal marking.

Range. Known only from the type locality, Phu Sri Tan Wildlife Sanctuary, Kalasin Province, and Phu Pha Namtip Non-hunting Area, Roi Et Province, eastern Thailand.

Natural history. In Phu Sri Tan, $R$. jarujini was found at night on a dried, rocky streambed (width $<5 \mathrm{~m}$ ), and it jumped into small pools when alerted. In Phu Pha Namtip, it was found at night perching on the leaves of trees $(<2 \mathrm{~m})$ along the bank of a small pond. No tadpoles or eggs were found in the pond, and calling males were absent in late October. All females had small ovaries, indicating a postbreeding condition. Frogs found associated with $R$. jarujini included Occidozyga lima (Gravenhorst, 1829), O. martensii (Peters, 1867), Rana nigrovittata (Blyth, 1856), Fejervarya limnocharis (Gravenhorst, 1829), Limnonectes gyldenstolpei (Andersson, 1916), Polypedates leucomystax (Gravenhorst, 1829), Microhyla fissipes Boulenger, 1884, M. berdmorei (Blyth, 1856), M. heymonsi Vogt, 1911, and M. pulchra (Hallowell, 1861).

Comparisons. Although the distinction between Rhacophorus and Polypedates is under debate, as noted above, $R$. jarujini $\mathrm{n}$. $\mathrm{sp}$. is assigned on the basis of osteology to Rhacophorus (having procoelous vertebral column and lacking parieto-squamosal arch of the frontoparietal) rather than to Polypedates (having diplasicoelous vertebral column and mostly having parieto-squamosal arch; Liem, 1970). Therefore, we compare with the new species only species listed as Rhacophorus by Frost (2004).

The dorsal ground color of $R$. jarujini is brown, which differentiates it from the following species that have a dorsum with the ground color green: $R$. arboreus (Okada and Kawano, 1924) and $R$. schlegelii (Günther, 1859) from the Japanese Main Islands; $R$. owstoni (Stejneger, 1907) and $R$. viridis (Hallowell, 1861) from the Ryukyus; $R$. arvalis Lue, Lai, and Chen, 1995, $R$. aurativentris Lue, Lai, and Chen, 1994, R. moltrechti Boulenger, 1908, R. prasiantus Mou, Risch, and Lue, 1983, and $R$. taipeianus Liang and Wang, 1978 from Taiwan; $R$. dennysii Blanford, 1881 from China; $R$. feae Boulenger, 1893 from China, Vietnam, Thailand, and Myanmar; R. maximus Günther, 1859 from China, Thailand, Nepal, and India; $R$. calcaneus Smith, 1924 and $R$. duboisi Ohler, Marquis, Swan, and Grosjean, 2000 from Vietnam; $R$. promianus Smith, 1924 (including $R$. tunkui Kiew, 1987) from Thailand and Malaysia; $R$. taroensis Smith, 1940 from Myanmar; R. malabaricus Jerdon, 1870 and $R$. pseudomalabaricus Vasudevan and Dutta, 2000 from India; $R$. nigropalmatus Boulenger, 1895 from India, Thailand, Malaysia, Sumatra and Borneo; $R$. reinwardtii (Schlegel, 1840) from Sumatra, Java, Malaysia, and China; $R$. dulitensis Boulenger, 1892 from Sumatra and Borneo; $R$. achantharrhena Harvey, Pemberton, and Smith, 2002 from Sumatra; R. kajau Dring, 1984 from Borneo; $R$. edentulus Mueller, 1894, R. georgii Roux, 1904, and R. monticola Boulenger, 1896 from Sulawesi.

Rhacophorus jarujini $\mathrm{n}$. sp. is distinguished from some species having skin modifications: $R$. angulirostris Ahl, 1927 
from Borneo and Sumatra; $R$. translineatus Wu, 1977 from China; and $R$. appendiculatus (Günther, 1859) from Malaysia to Sumatra, Borneo, and the Philippines have a markedly pointed snout, and the last two species have an anal flap like $R$. rhodopus Liu and $\mathrm{Hu}, 1959$ from China and $R$. namdaphaensis Sarkar and Sanyal, 1985 from India. Rhacophorus appendiculatus also has a crenulated fringe along the tarsus, as do $R$. bisacculus Taylor, 1962 from Thailand and India and $R$. exechopygus Inger, Orlov, and Darevsky, 1999 from Vietnam. The following species all have a dermal flap or projections at the heel: Rhacophorus baluensis Inger, 1954 and $R$. gauni (Inger, 1966) from Borneo; $R$. verrucopus Huang, 1983 from China; $R$. bipunctatus Ahl, 1927 from India, Tibet, Myanmar, Thailand, and Malaysia; $R$. barisani Harvey, Pemberton, and Smith, 2002 and $R$. catamitus Harvey, Pemberton, and Smith, 2002 from Sumatra; $R$. margaritifer (Schlegel, 1837) from Java; $R$. pardalis Guenther, 1859 from Malaysia, Sumatra, Borneo, and the Philippines; R. hoanglienensis Orlov, Lathrop, Murphy, and Ho, 2001 and $R$. orlovi Ziegler and Köhler, 2001 from Vietnam; and $R$. namdaphaensis, $R$. rhodopus, and $R$. translineatus. In having smooth dorsal skin, $R$. jarujini differs from species with a tuberculate or rugose dorsum ( $R$. calcadensis Ahl, 1927 and $R$. tuberculatus Anderson, 1871 from India; $R$. verrucosus Boulenger, 1893 from Vietnam, Cambodia, Myanmar, and India; R. everetti Boulenger, 1894 from the Philippines and Borneo).

In $R$. jarujini, a broad web on the fourth finger reaches the distal subarticular tubercle or base of the disk. In some species, webs between the fingers are less developed than in $R$. jarujini, and webbing is limited at most to the base of the subarticular tubercle on the fourth finger ( $R$. baliogaster Inger, Orlov, and Darevsky, 1999 from Vietnam; $R$. poecilonotus Boulenger, 1920 and $R$. modestus Boulenger, 1920 from Sumatra; $R$. everetti; $R$. bisacculus). In contrast, other species have hand webbing better developed than in $R$. jarujini. The web reaches the base of the disk on both sides of the third finger as a broad sheet in $R$. annamensis Smith, 1924 from Vietnam (including $R$. notater Smith, 1924; Matsui, 2005); $R$. robinsonii Boulenger, 1903 from Thailand and Malaysia; and $R$. harrisoni Inger and Haile, 1959, R. rufipes Inger, 1966, and $R$. fasciatus Boulenger, 1895 from Borneo. In $R$. jarujini, only the outer side of the third finger is sometimes fully webbed.

Although the degree of web development on the fourth finger is similar, R. bimaculatus (Peters, 1867) from the Philippines and $R$. cyanopunctatus Manthey and Steiof, 1998 from Thailand, Malaysia, Borneo, and Sumatra have a dark mask on the sides of the head, and blue spots on the flanks. Rhacophorus turpes Smith, 1940 from Myanmar has a much narrower head than $R$. jarujini, and the dorsum is immaculate or scattered with dots. Rhacophorus lateralis (Boulenger, 1883) from India has a series of dorsolateral markings and much less developed toe webbing.

\section{DISCUSSION}

Dubois (1987) divided members of Rhacophorus (sensu lato) into two subgenera, Leptomantis and Rhacophorus, and further subdivided the latter subgenus into several species groups. Among about 60 species of Rhacophorus mentioned above, $R$. jarujini is superficially similar to members of the fasciatus group ( $R$. fasciatus and $R$. harrisoni) or the pardalis group ( $R$. annamensis [including $R$. notater, see above], $R$. pardalis, and $R$. robinsonii). Although Dubois (1987) noted that his classification was chiefly based on larval morphology, data are lacking for many species. Thus, the reasons for Dubois' (1987) placement of the abovementioned species in the pardalis group is unclear. Similarly, because no larvae are yet known for $R$. jarujini, its classification remains uncertain. Species of the pardalis group, as well as $R$. catamitus from Sumatra described more recently (Harvey et al., 2002), are especially similar to $R$. jarujini in dorsal color pattern. Dorsal coloration, however, must be adaptive in its cryptic function and is expected to exhibit convergence in many different lineages of Old World treefrogs.

Rhacophorus jarujini was found in the center of the Thai-Lao Dry Plateau (Inger, 1999), where the native vegetation scarcely remains because of the paucity of large forest reserves or conservation areas. Due partly to this habitat modification and partly to poor sampling to date, the number of anuran species known from the plateau is small. In addition, the scarcity of mountain streams in this region seems to restrict the distribution of anuran species to those that breed in ponds or develop directly. Inger (1999) listed 35 species from the plateau, of which only two (Chirixalus hansenae [Cochran, 1927] and $R$. bisacculus) were considered endemic to the region; $R$. bisacculus has now been reported from outside Thailand (Frost, 2004). Interestingly, both these species are rhacophorids. Inger (1999: 457) listed as endemic another rhacophorid, Philautus parvulus (Boulenger, 1893), but this species is actually not endemic to the region (Inger, 1999: 480). Thus, only $C$. hansenae and $R$. jarujini can presently be regarded as endemic to the Thai-Lao Dry Plateau. A more intensive survey in this region would likely detect additional undescribed species, as indicated by the discovery of $R$. jarujini, but this should be done quickly, because the modification of amphibian habitats is in progress.

\section{ACKNOWLEDGMENTS}

We thank J. Nabhitabhata, H. Ota, K. Araya, M. Toda, and S.L. Cheng for help in the field, T. Hikida for help in statistical analyses, and H. Ota, Y. Shibata, I. Das, and U. Manthey for providing literature or information. The National Research Council of Thailand and the Royal Forest Department of Thailand granted permission for fieldwork in Thailand. We thank S. Tunhikorn for help in obtaining permission. We are grateful to C. McCarthy and B. T. Clarke (BM), M. S. Hoogmoed (RMNH), N. Ananjeva and N. Orlov (ZIL), R. Günther and U. Manthey (ZMB), A. Haenggi (NHMB), G. Doria (MSNG), and A. Dubois and A. Ohler (MNHNP) for allowing MM to examine specimens under their care. K. Nishikawa and T. Shimada prepared radiographs and photographs. This study was supported by grants under The Monbusho International Scientific Research Program (Field Research, Nos. 06041066, 08041144, and 10041166) to MM.

\section{REFERENCES}

Dubois A (1987) Miscellanea taxinomica [sic] batrachologica (I). Alytes 5: 7-95

Duellman WE (Ed) (1999) Patterns of Distribution of Amphibians: A Global Perspective, Johns Hopkins University Press, Baltimore

Fei L, Ye CY, Jiang JP, Xi F, Huang, YZ (2004) An Illustrated Key to Chinese Amphibians. Sichuan Publishing Group and Sichuan 
Publishing House of Science and Technology, Chengdu

Frost DR (Ed) (1985) Amphibian Species of the World: A Taxonomic and Geographic Reference. Allen Press Inc. and Association of Systematics Collections, Lawrence

Frost DR (2004) Amphibian species of the world: an online reference, Version 3.0 (22 August, 2004). American Museum of Natural History, New York, Electronic Database accessible at http:/ /research.amnh.org/herpetology/amphibia/index.html.

Harvey BH, Pemberton AJ, Smith EN (2002) New and poorly known parachuting frogs (Rhacophoridae: Rhacophorus) from Sumatra and Java. Herpetol Monogr 16: 46-92

Inger RF (1999) Distribution of amphibians in Southern Asia and adjacent islands. In "Patterns of Distribution of Amphibians: A Global Perspective" Ed by WE Duellman, Johns Hopkins University Press, Baltimore, pp 445-482

Inger RF, Orlov N, Darevsky I (1999) Frogs of Vietnam: A report on new collections. Fieldiana Zool NS 92: 1-46

Jiang SP, Hu SQ, Zhao EM (1987) The approach of the phylogenetic relationship and the supraspecific classification of $14 \mathrm{Chi}-$ nese species of tree frogs (Rhacophoridae). Acta Herpetol Sinica NS 6: 27-42

Liem SS (1970) The morphology, systematics and evolution of the Old World tree frogs (Rhacophoridae and Hyperoliidae). Fieldiana Zool 57: 1-145

Maeda N, Matsui M (1999) Frogs and Toads of Japan, Rev Ed, Bunichi Sogo Shuppan, Tokyo

Malkmus R., Manthey U, Vogel G, Hoffman P, Kosuch J (2002) Amphibians and Reptiles of Mount Kinabalu (North Borneo). ARG Gantner Verlag Kommanditgesellschaft, Ruggell

Manthey U, Steiof C (1998) Rhacophorus cyanopunctatus sp. n. (Anura: Rhacophoridae), ein neuer Flugfrosch von der Malaiischen Halbinsel, Sumatra und Borneo. Sauria 20: 37-42

Matsui M (1984) Morphometric variation analyses and revision of the Japanese toads (Genus Bufo, Bufonidae). Contrib Biol Lab Kyoto Univ 26: 209-428
Matsui M (2000) Batrachology of Japan and adjacent regions -a systematic review. Comp Bioch Physiol B 126: 247-256

Matsui M (2005) Taxonomic relationships of two species of Rhacophorus from Vietnam (Amphibia, Rhacophoridae). Cur Herpetol 24: 91-93

Matsui M, Orlov N (2004) A new species of Chirixalus from Vietnam (Anura: Rhacophoridae). Zool Sci 21: 671-676

Matsui M, Wu GF (1994) Acoustic characteristics of treefrogs from Sichuan, China, with comments on systematic relationship of Polypedates and Rhacophorus (Anura, Rhacophoridae). Zool Sci 11: 485-490

Matsui M, Chan-Ard T, Nabhitabhata J (1996) Distinct specific status of Kalophrynus pleurostigma interlineatus (Anura, Microhylidae). Copeia 1996: 440-445

Matsui M, Nabhitabhata J, Panha S (1998) A new Ansonia from northern Thailand (Anura, Bufonidae). Herpetologica 54: 448454

Matsui M, Nabhitabhata J, Panha S (1999) On Leptobrachium from Thailand with a description of a new species (Anura: Pelobatidae). Jpn J Herpetol 18: 19-29

Matsui M, Khonsue W, Nabhitabhata J (2005) A new Ansonia from Isthmus of Kra, Thailand (Amphibia, Anura, Bufonidae). Zool Sci 22: 809-814

Taylor, EH (1962) The amphibian fauna of Thailand. Univ Kansas Sci Bull 43: 265-599

Tian WW, Jiang YM (Eds) (1986) Identification Manual of Chinese Amphibians and Reptiles. Science Press, Beijing

Wilkinson JA, Drewes RC, Tatum OL (2002) A molecular phylogenetic analysis of the family Rhacophoridae with an emphasis on the Asian and African genera. Molec Phylogenet Evol 24: 265273

Zhao EM, Adler K (1993) Herpetology of China. SSAR, Oxford, Ohio

(Received November 10, 2005 / Accepted December 21, 2005) 